\title{
European Journal of Physical and Rehabilitation Medicine
}

EDIZIONI MINERVA MEDICA

\section{ARTICLE ONLINE FIRST}

This provisional PDF corresponds to the article as it appeared upon acceptance.

A copyedited and fully formatted version will be made available soon.

The final version may contain major or minor changes.

\section{Pain extent is more strongly associated with disability, psychological factors, and neck muscle function in people with non-traumatic versus traumatic chronic neck pain - a cross sectional study}

Inge RIS, Marco BARBERO, Deborah FALLA, Mads H LARSEN, Martin K NIELSEN, Karen SøGAARD, Birgit JUUL-KRISTENSEN

European Journal of Physical and Rehabilitation Medicine 2018 Aug 27

DOI: 10.23736/S1973-9087.18.04977-8

Article type: Original Article

(C) 2018 EDIZIONI MINERVA MEDICA

Article first published online: August 27, 2018

Manuscript accepted: July 27, 2018

Manuscript revised: June 27, 2018

Manuscript received: September 7, 2017

Subscription: Information about subscribing to Minerva Medica journals is online at: http://www.minervamedica.it/en/how-to-order-journals.php

Reprints and permissions: For information about reprints and permissions send an email to: journals.dept@minervamedica.it - journals2.dept@minervamedica.it - journals6.dept@minervamedica.it 


\section{Pain extent is more strongly associated with disability, psychological factors, and neck muscle function in people with non-traumatic versus traumatic chronic neck pain-a cross sectional study}

Inge Ris ${ }^{1,2,}{ }^{*}$, Marco Barbero ${ }^{3}$, Deborah Falla ${ }^{4}$, Mads H. Larsen ${ }^{1,}$ Martin N. Kraft ${ }^{1}$, Karen Søgaard ${ }^{5}$, Birgit Juul-Kristensen ${ }^{1,6}$

${ }^{1}$ Research Unit of Clinical Biomechanics, Department of Sports Science and Clinical Biomechanics, University of Southern Denmark, Odense, Denmark

${ }^{2}$ Metropolitan University College, Copenhagen N, Denmark

${ }^{3}$ Rehabilitation Research Laboratory 2rLab, Department of Business, Health and Social Care, University of Applied Sciences and Arts of Southern Switzerland (SUPSI), Manno, Switzerland,

${ }^{4}$ Centre of Precision Rehabilitation for Spinal Pain (CPR Spine), School of Sport, Exercise and Rehabilitation Sciences, College of Life and Environmental Sciences, University of Birmingham, United Kingdom

${ }^{5}$ Research Unit for Physical Activity and Health in Working Life, Department of Sports Science and Clinical Biomechanics, University of Southern Denmark, Campusvej 55, 5230 Odense M,

${ }^{6}$ Bergen University College, Institute of Occupational Therapy, Physiotherapy and Radiography, Department of Health Sciences, 5020 Bergen, Norway,

*Corresponding Author: Inge Ris, University of Southern Denmark, Campusvej 55, 5230

Odense M, Denmark. Email: iris@ @ealth.sdu.dk 


\begin{abstract}
BACKGROUND: Neck pain is presented with a variety of symptoms. Pain drawings are used in the clinical assessment of people with neck pain. Pain extent based upon pain drawings can be associated with different factors. However, the relation between pain extent and function limitations in people with neck pain is unknown.
\end{abstract}

AIM: To explore the associations between pain extent extracted from pain drawings, and self-reported neck pain related disability, quality of life, depression, self-reported neck function, cervical muscle function, and range of motion in a chronic neck pain population and possible differences depending on the onset of pain being traumatic or not.

DESIGN: Observational cross-sectional study.

SETTING: Primary and secondary healthcare.

POPULATION: People with chronic neck pain $(n=200)$ of traumatic $(n=120)$ or nontraumatic $(n=80)$ origin.

METHODS: Outcome measures: Pain extent, Short Form 36 Health Survey Physical and Mental Component Summary (SF36-PCS/MCS), TAMPA Scale of Kinesiophobia (TSK), Beck Depression Inventory-II (BDI-II), Neck Disability Index (NDI), Craniocervical Flexion Test (CCFT), Cervical Extension Test (CE), and Cervical Range of Motion (ROM). Correlations were calculated using Spearman or Pearson correlation coefficients. Correlation between pain extent and outcomes were calculated for all participants collectively and then separately for those with a traumatic versus non-traumatic neck pain.

RESULTS: Overall, significant positive correlations were observed between pain extent and NDI $(r=0.33 ; p<0.001)$, BDI-II $(r=0.29 ; p<0.001)$, CCFT $(r=-0.24 ; p=0.001)$ and CE $(r=$ $-0.19 ; \mathrm{p}=0.006$ ). No difference in pain extent between those with traumatic (mean \pm Standard Deviation: $7.6 \pm 6.7 \%)$ or non-traumatic onset $(7.4 \pm 6.8 \%)$. Pain extent correlated moderately with NDI, BDI-II, TSK, CCFT and CE in those with non-traumatic onset, but weakly with NDI, BDI-II, CCFT and CE in those with trauma-induced chronic neck pain. 
CONCLUSIONS: Pain extent is correlated with patient-reported neck function, depression and muscle test performance in people with chronic neck pain. These correlations were strongest in those with non-traumatic neck pain.

CLINICAL REHABILITATION IMPACT: Patients presenting with larger pain areas show poorer psychological and physical function. Pain drawings can therefore indicate a need for addressing these functions in management of person with chronic neck pain.

Key words: Neck Pain, Pain Drawing, Pain Extent, Traumatic Neck Pain, Non-traumatic Neck Pain 


\section{INTRODUCTION}

Neck pain is a common condition ranking 4th highest as a cause of years lived with disability [1]. Patients with chronic neck pain often present with a variety of other signs and symptoms. These may include physical impairments as decreased cervical mobility and altered neuromuscular function of the flexor [2] and extensor [3] muscles, as well as psychological distress, depression and fear avoidance [4], and reduced quality of life [5]. The extent of some of these factors may depend on the origin of pain with differences observed between those with traumatic versus non-traumatic neck pain [6-8]. For instance, certain sub-groups of patients with chronic neck pain typically present with more widespread pain, i.e. those with neck pain induced by a whiplash injury [9] and those with neck pain with neuropathic features.

Pain drawings are widely used in the clinical assessment of people with neck pain [10] as they allow the patient to describe their perceived pain localisation and pain extent. Larger pain extent may reflect biological factors (e.g. central sensitization, and inflammatory system response), and psychological factors, and may be associated with poorer neck function. Recent work showed that pain extent is associated with greater disability, depression and lower self-efficacy in individuals with whiplash-associated disorders [11]. Moreover, larger pain extent is associated with higher pain intensity in women with fibromyalgia [12]. An association between the extent of pain and pain catastrophizing has also been observed in people with neck-shoulder pain [13]. Pain extent is recorded as a factor related to poorer physical functioning [14]. However, no study has evaluated the relation between pain extent and function limitations in people with neck pain. Based upon our hypothesis that larger pain extent would be associated with poorer psychological and physical functioning in people with chronic neck pain, we analysed pain extent and its association with psychological health, quality of life, and neck function as a secondary analysis to a recently reported randomised controlled study [15]. Additionally we hypothesised that pain extent would be larger and the associations stronger in people with trauma-induced neck pain versus those with non-traumatic neck pain given that people with neck pain of traumatic onset typically report greater pain severity $[8,16]$. Thus the first objective of this study was to evaluate associations between pain extent and quality of life, fear avoidance, depression, selfreported and measured neck function, and cervical range of motion in people with neck pain regardless of the origin of their pain (traumatic and non-traumatic onset of neck pain) and 
the second objective to evaluate differences in pain extent between the two groups (traumatic or non-traumatic), as well as the associations between pain extent and the selected variables for each group separately.

\section{MATERIALS AND METHODS}

\section{Design}

This study is an observational cross-sectional study and conducted as secondary analysis of baseline data from a randomised paralleled two-group trial [15]. The trial was registered at www.ClinicalTrials.gov (NCT01431261). The Regional Scientific Ethics Committee of Southern Denmark approved the study (S-20100069) 21 ${ }^{\text {st }}$ February 2011 (Chairman Birger Møller). Participants were recruited in the period of March 2012 to September 2014. This study conformed to The Declaration of Helsinki 2008, fulfilling all ethical requirements and reporting of the present study is guided by the STROBE checklist [17]. Participants provided written informed consent.

\section{Settings}

The patients were recruited from both primary (eight physiotherapy clinics) and secondary health care locations (two hospital spine centres, one hospital outpatient clinic and one municipal rehabilitation centre). The recruitment sites were in urban or rural areas and spread across the middle and western parts of Denmark. Both spine centres and the rehabilitation centre were specialised in treating patients with musculoskeletal spinal disorders. The hospital outpatient clinic was specialised in treating neurological and headache patients. Patients recruited from the physiotherapy clinics had been referred from general practitioners for physiotherapy treatment. Patients recruited from secondary health care centres had been referred from general practitioners, chiropractors or specialised medical doctors to the involved centres.

\section{Participants}

Patients were informed about the option of participating via in-clinic advertisements, by their treating clinician or at their first contact with the health care unit. Inclusion criteria were minimum age of 18 years, neck pain for at least six months with either traumatic or nontraumatic onset, reduced physical neck function (defined as Neck Disability Index score of at least 10 out of 50), completed diagnostic procedures (e.g. medical investigations, diagnostic imaging), ability to read and understand Danish. Patients were allowed to have pain in other body regions as long as the primary pain area was their neck. Exclusion criteria were radiculopathies (clinically tested by: positive Spurling test, relief on cervical traction and 
positive brachial plexus provocation test on the affected side), engagement in experimental or progressive medical treatment, unstable social and/or working situation, pregnancy, known current fractures, severe depression (defined as Beck Depression Index score over 29 [18]), or other known co-existing medical conditions.

\section{Assessment procedures}

Local physiotherapists screened patients with neck at their first contact with the clinic for eligibility as participant of the study using a checklist for inclusion and exclusion criteria as described above, being trained in the initial screening procedure by the first author (IR). After inclusion, two physiotherapists assessed the patients. A standardised test protocol was used for all assessments; the physical tests were conducted in the same order for all patients followed by completion of the questionnaires within the same session. All clinical tests are described in detail as well as the inter- and intra-reliability, construct and discriminative validity and minimal detectable changes [30].

\section{Outcome measures}

Age, sex, duration of neck pain, employment status, educational level and sleep pattern were registered as socio-demographic characteristics.

\section{Pain Extent}

The patients completed a pain drawing by shading their perceived location and extent of pain on two paper body charts (frontal and dorsal view of the body) using a pencil. Patients were instructed to draw their perceived pain over the last two weeks. Subsequently, all completed paper body charts were digitized at 144 dpi using a commercially available scanner. The shaded areas were encircled and copied onto a digital body chart by two trained operators using image analysis software (Inkscape version 0.48.5). The digital marking of the pain drawing was performed according to the following guidelines: an area marked digitally inside one continuous line indicated a pain area; in case of a single line, the area was marked by drawing closely to the line on both sides. The density of shading of the marked area was not taken into account. Any area of pain drawn outside of the body chart borders was not included in the analysis. Based on automatic pixel counting, the marked area was expressed as a percentage of total body chart area (see Figure 1). The current procedure of digitalizing pain drawings has been previously described and its reliability confirmed [19, 20]. Pain extent was computed using software that was developed and tested in a previous study [10]. Patient-reported outcomes 
Quality of life was measured with the Short Form 36 Health Survey, a generic questionnaire of functioning and well-being, with high reliability and validity and tested both in general and disease-specific populations in Denmark [21, 22]. The Standardised Physical Component Summary (SF36-PCS) and Mental Component Summary Scores (SF36-MCS) were generated.

Fear avoidance was measured with the TAMPA Scale of Kinesiophobia (TSK), a questionnaire with 17-items, measuring fear of movement, injury and re-injury (range: 1768). A score above 37 indicates a high degree of kinesiophobia [23]. TSK demonstrates adequate internal consistency (Cronbach's Alpha ranges from 0.70-0.81) and good test-retest reliability ( $\mathrm{r}=0.78)$. The test shows acceptable concurrent validity, correlating TSK with other self-reported measures of pain-related fear ( $r$-values range from 0.54-0.60) and construct validity, tested among Danish workers [24].

Depression was measured with the Beck Depression Inventory-II (BDI-II), a 21-item questionnaire of depressive symptoms including items assessing both cognitive and somatic complaints associated with depression. All the scores are summed into one score, ranging from $0-63$, with a total score less than 14 indicating minimal or no depression, 14-19 mild depression, 20-28 moderate depression, and >28 severe depression [25]. The BDI-II has high validity and reliability in measuring depressive symptoms, including acceptable testretest reliability $(\mathrm{r}=0.79)$ in a non-clinical population and outpatient population [26]. Self-reported neck pain and disability was measured with the Neck Disability Index (NDI); scores range from 0-50, with higher scores representing greater disability. The overall score (out of 50) was calculated by summing the responses to each individual item. The internal consistency is acceptable (Cronbach's alpha 0.864) and test-retest reliability high (intra-class correlation 0.94) [27]. The questionnaire is found to be valid and reliable in primary care in Denmark [28].

\section{Clinical tests}

Cervical muscle function was tested with the craniocervical flexion test (CCFT) to evaluate deep cervical flexor muscle function [29] and the cervical extensor test (CE), to evaluate cervical extensor muscle function [30].

The CCFT is a standardized test that consists of five incremental movements of increasing craniocervical flexion range of motion. Performance was guided by visual feedback from an air-filled pressure sensor (Stabilizer ${ }^{\mathrm{TM}}$, Chattanooga Group Inc. USA) placed sub-occipitally behind the subject's neck and initially inflated to a baseline pressure of $20 \mathrm{mmHg}$. The test 
was stopped at the point that the patient displayed compensatory strategies (e.g. retraction or over activity of the superficial flexors) and the pressure level below this level was registered. The CCFT performance was divided into three categories: $22 \mathrm{mmHg}, 24 \mathrm{mmHg}$, and 26$30 \mathrm{mmHg}$.

The CE test measured the duration that the patient could hold the head extended, while lying in prone with the head and neck over the edge of the bed. The participant performed cervical extension while keeping the craniocervical region in a neutral position until extension in the middle or upper cervical column occurred. The participant wore a headband with a laser light placed on the top of their head. The laser beam was projected to a target on the floor and the participant was instructed to hold the same position with the laser beam in the centre of the target for as long as possible. The test was terminated after $120 \mathrm{~s}$ or when the laser beam moved away from the centre of the target, and duration was recorded in seconds. Each participant performed the test three times with a rest period of less than five minutes between repetitions and the best result was recorded [29].

Cervical Range of Movement (ROM) was measured for flexion-extension, right-left lateral flexion, and right-left rotation with the patient in upright sitting. An inclinometer was used to measure flexion, extension and lateral flexion in degrees. For rotation, a semi-circular goniometer was placed upon the patients shoulders measuring cervical rotation to the nearest five degrees.

All of the above clinical tests are fully described elsewhere and their intra- and interexaminer reliability valuated in the settings used in this study (Intraclass Correlations for CCFT: 0.63-0.86; CE: 0.75-0.90; ROM: 0.80-0.94) [30].

\section{Data analysis}

No formal a priori sample size calculation was conducted specifically for the present analyses, as the current data represent baseline data from a clinical trial exploring the effect of training and exercises in chronic neck pain patients [15]. A detailed description described how potential biases in data collection were addressed are described elsewhere [15]. All continuous data were checked for normality using Shapiro Wilks test and QQ plots. Data of SF36-MCS, SF36-PCS and TSK were normally distributed, whereas data of BDI-II and NDI, and data of CCFT, CE, ROM, and pain extent were not normally distributed. Correlations were calculated using Spearman or Pearson correlation coefficients depending on the distribution of the data. Correlation between pain extent and SF36-PCS, SF36-MCS, TSK, BDI-II, NDI, ROM, and CCFT and CE were calculated for all participants collectively 
and then separately for those with a traumatic versus non-traumatic neck pain. A weak statistical correlation was considered with correlation coefficients $<0.3$, a moderate correlation from $0.3-0.5$ and a strong correlation $>0.5$ [31]. Statistical significance was set to $\alpha=0.05$. All statistical analyses were carried out with the Statistical Package for Social Sciences (version 22.0.0, IBM, New York, USA). Missing data were not entered in the analyses.

\section{RESULTS}

\section{Patient characteristics}

A total of 200 patients were included: 120 with neck pain of traumatic origin and 80 with neck pain of non-traumatic origin. The characteristics of both groups are fully described in a former study [8]. Briefly, the majority in both groups were women (75\%), those with neck pain of traumatic onset were on average 4 years younger (mean \pm SD: $43.5 \pm 11.4$ years) compared to those in the non-traumatic group ( $47.6 \pm 11.4$ years) but this difference was not significant. The average duration of symptoms was almost 9.0 years (107.8 \pm 101.8 months), however, those with neck pain of traumatic origin had significantly $(\mathrm{p}<0.01)$ shorter duration of symptoms (88.1 \pm 89.2 months) compared to those with non-traumatic origin (138.3 \pm 112.7 months). Both groups had the same educational level, with more than $80 \%$ skilled, $8 \%$ without education, and almost $11 \%$ having an academic level. The unemployment rate was similar in both groups (8\% and $9 \%$ for those with traumatic versus non-traumatic onset, respectively). In both groups, more than half were occupationally active: $54 \%$ of those with neck pain of traumatic origin and $61 \%$ of those with non-traumatic origin. The remaining participants were retired, on sick leave or undertaking education. Across both groups, $67 \%$ experienced sleep disturbances.

Across both groups the pain extent was $7.5 \pm 6.7 \%$ of the total body chart area; those with neck pain of traumatic origin had an average pain extent of $7.6 \pm 6.7 \%$ whereas those with non-traumatic origin had an average pain extent of $7.4 \pm 6.8 \%$.

For the total cohort, mean scores of the SF36-PCS and SF36-MCS were $35.4 \pm 7.6$ and 46.3 \pm 10.7 , respectively. BDI-II was $13.9 \pm 8.7$ indicating mild depression, TSK score was 37.8 \pm 6.9 , indicating a high degree of kinesiophobia [32], and the average NDI score was $21.7 \pm$ 7.7, indicating moderate neck disability [33] (Table I). Performance outcomes of the clinical tests for the entire cohort are presented in Table I.

(Table I) 


\section{Correlation between pain extent and other clinical features comparing the traumatic and non-traumatic groups}

Across the entire cohort, NDI was moderately correlated to pain extent $(r=0.33 ; p<0.001)$ indicating that larger pain areas were associated with higher NDI scores. This correlation was stronger for the group with non-traumatic neck pain $(r=0.45, p<0.001)$ compared to those with neck pain of traumatic origin $(r=0.22, p=0.02)$. Pain extent was also weakly correlated to both BDI-II and TSK $(r=0.29 ; \mathrm{p}<0.001$ and $\mathrm{r}=0.21 ; \mathrm{p}<0.05$, respectively), indicating that larger pain extent was associated with higher depression and greater kinesiophobia scores across the entire group. Those with non-traumatic neck pain displayed a moderate correlation between pain extent and both variables $(r=0.42, p<0.01$ and $r=0.31$, $\mathrm{p}<0.01$ for BDI-II and TSK respectively), whereas those with neck pain of traumatic origin had only a weak correlation between pain extent and BDI-II $(r=0.22, p=0.02)$, and a nonsignificant correlation between pain extent and TSK. Correlations between pain extent and SF36-PCS, SF36-MCS and ROM were non-significant.

For the clinical tests, correlations between pain extent and CCFT and CE performance were weak and negative $(r=-0.23 ; p<0.01$ and $r=-0.20 ; p<0.01$ respectively), indicating that larger pain extent was associated with poorer performance on both tests (Table II).

(Table II)

\section{DISCUSSION}

The current study is the first to examine the relationship between pain extent and patientreported outcomes on neck function, quality-of-life and psychological factors, in addition to clinical tests for neck muscle function in people with chronic neck pain. When considering the full sample of patients with either non-traumatic and trauma induced neck pain, moderate correlations were observed between pain extent and perceived neck disability, and weak correlations were observed between pain extent and the level of depression, kinesiophobia as well as performance on clinical tests for neck muscle function. This is supported by a previous study, showing that pain extent explained 5-6\% of the variance of NDI scores in patients with chronic whiplash associated disorders [34]. By comparing the subgroups in the current sample, it was shown that correlation for those with non-traumatic neck pain were consistently on a moderate level for all outcomes whilst they were only weak for those with trauma-induced neck pain, which is in contrast to our hypothesis. The moderate correlation between pain extent and NDI indicates that other variables may explain the variance in pain 
extent, such as pain intensity and kinesiophobia [34]. Yet, only weak correlations were observed between pain extent and depression as well as kinesiophobia. This finding is in line with a previous systematic review [35] which concluded that pain drawings (mainly low back pain) cannot be used as an indicator of the patients' psychological state. A more recent review confirmed that pain drawings from subacute/chronic low back pain patients cannot detect psychological features [36]. However, comparison with other studies is challenging, as use of standardised body charts as well as methods for analysing these are mostly lacking. This may be the reason for contrasting results with a recent study in patients with neckshoulder pain reporting a significant correlation between non-organic pain (determined from pain drawings) and pain catastrophizing [12].

A previous study, using the same body charts as this current study, reported an association between pain extent and NDI, depression and self-efficacy in people with whiplash associated disorders [10]. This finding was confirmed in the current study with weak correlations observed between pain extent and NDI as well as BDI-II. Unique to this study we also evaluated pain extent in people with neck pain of non-traumatic origin and showed that the correlation between pain extent and NDI, BDI-II and TSK was stronger compared to the correlations observed for the group with trauma-induced neck pain. The complexity and severity of symptoms is reported to be greater in those with neck pain of traumatic origin including additional symptoms such as post-traumatic stress disorder [37], and central sensitisation [38] which were not considered in the current study.

This study also revealed significant correlations between pain extent and performance on tests of neck muscle function although these correlations were weak in those with neck pain of traumatic origin and moderate in those with a non-traumatic origin. Previous work has shown stronger correlations between pain intensity and performance on the CCFT and CE $[39,40]$. Therefore, other dimensions such as pain intensity may be stronger indicators of altered neck muscle function than pain extent.

\section{Methodological considerations}

The current work included a large sample size and the study was conducted across multiple clinical centres adding to the strengths of this study. The participants were referred to the clinics via usual procedures and were part of the normal population of the centres. Those centres included both urban and rural areas, primary and secondary care, as well as different geographic areas strengthening the external validity of the results. But, records of those tested for eligibility but not entering the study were for practical reasons not possible to 
obtain. However, this is not considered to influence the outcome of this current study as this is a studying correlation between different outcomes. Anecdoticly, the eligible patients excluded were few. Therefore, we assume the external validity to be sufficient to transfer the results of the study in daily clinical practice. The data collection was based upon methods with a moderate to strong intra-class correlation and inter-tester reliability [10, 13, 23, 30, $41,42]$ and collected by the same two assessors according to a rigorous standardised protocol. Despite recruitment from different centres, data collection was performed with the same test equipment and the test setting was similar across recruitment locations. The analyses of pain drawings were executed by two experienced investigators following established procedures.

Limitations of the study include the fact that the clinical tests and questionnaires used for inclusion of the participants were delivered by different physiotherapists at these different centres, which may have introduced some variability; nevertheless, this variability was minimised since all physiotherapists were carefully trained in the procedures by the same instructor. Also, there are no records of those excluded after tested for eligibility, which weakens the external validity of the study.

\section{Clinical interpretations}

The extent of pain, expressed in pain drawings, is associated with higher self-perceived neck disability and can be an indicator for psychological screening, especially for non-traumatic neck pain patients.

\section{CONCLUSIONS}

Patients with chronic neck pain that describe larger pain areas are likely to present with greater self-perceived disability, depression, kinesiophobia and poorer muscle function. These associations were strongest in those with neck pain of non-traumatic onset and only weak in those with neck pain of traumatic onset. Pain drawings can therefore indicate a need for addressing these functions in management of person with chronic neck pain. 


\section{REFERENCES}

1] Hoy D, March L, Woolf A, Blyth F, Brooks P, Smith E, et al. The global burden of neck pain: estimates from the global burden of disease 2010 study. Ann Rheum Dis. 2014;7:130915.

[2] Falla D, O'Leary S, Farina D, Jull G. The change in deep cervical flexor activity after training is associated with the degree of pain reduction in patients with chronic neck pain. Clin J Pain. 2012;28: 628-34.

[3] Fernandez-de-las-Penas C, bert-Sanchis JC, Buil M, Benitez JC, burquerque-Sendin F. Cross-sectional area of cervical multifidus muscle in females with chronic bilateral neck pain compared to controls. J Orthop Sports PhysTher. 2008;38:175-80.

[4] Sterling MPTP, Carroll LJP, Kasch HMDP, Kamper SJPTP, Stemper BP. Prognosis After Whiplash Injury: Where to From Here? Discussion Paper 4. Spine. 201;36 Supplement:S330-S4.

[5] Yalcinkaya H, Ucok K, Ulasli AM, Coban NF, Aydin S, Kaya I, et al. Do male and female patients with chronic neck pain really have different health-related physical fitness, depression, anxiety and quality of life parameters? Int J Rheum Dis. 2014; May

[6] Chien A, Sterling M. Sensory hypoaesthesia is a feature of chronic whiplash but not chronic idiopathic neck pain. Man Ther. 2010;15:48-53.

[7] Woodhouse A, Vasseljen O. Altered motor control patterns in whiplash and chronic neck pain. BMC Musculoskelet Disord. 2008;9:90.

[8] Ris I, Juul-Kristensen B, Boyle E, Kongsted A, Manniche C, Søgaard K. Chronic Neck Pain Patients with Traumatic or Non-traumatic Onset: Differences in Characteristics. A cross-sectional study. Scan J Pain. 2017;14:1-8.

[9] Curatolo M. Diagnosis of altered central pain processing. Spine. 2011;36:S200-4.

[10] Barbero M, Moresi F, Leoni D, Gatti R, Egloff M, Falla D. Test-retest reliability of pain extent and pain location using a novel method for pain drawing analysis. Eur J Pain. 2015;8:1129-38.

[11] Falla D, Peolsson A, Peterson G, Ludvigsson ML, Soldini E, Schneebeli A, et al. Perceived pain extent is associated with disability, depression and self-efficacy in individuals with whiplash-associated disorders. Eur J Pain. 2016;9:1490-501.

[12] Barbero M, Fernandez-de-Las-Penas C, Palacios-Cena M, Cescon C, Falla D. Pain extent is associated with pain intensity but not with widespread pressure or thermal pain sensitivity in women with fibromyalgia syndrome. Clin Rheumatol. 2017;6:1427-32. 
[13] Hayashi K, Arai YC, Morimoto A, Aono S, Yoshimoto T, Nishihara M, et al. Associations between pain drawing and psychological characteristics of different body region pains. Pain Pract. 2015;15:300-7.

[14] Walker BF, Losco CD, Armson A, Meyer A, Stomski NJ. The association between pain diagram area, fear-avoidance beliefs, and pain catastrophising. Chiropr Man Therap. 2014;22:5.

[15] Ris I, Sogaard K, Gram B, Agerbo K, Boyle E, Juul-Kristensen B. Does a combination of physical training, specific exercises and pain education improve health-related quality of life in patients with chronic neck pain? A randomised control trial with a 4-month follow up. Man Ther. 2016;26:132-40.

[16] Anstey R, Kongsted A, Kamper S, Hancock MJ. Are People With Whiplash-Associated Neck Pain Different From People With Nonspecific Neck Pain? J Orthop Sports Phys Ther. 2016;10:894-901.

[17] von Elm E, Altman DG, Egger M, Pocock SJ, Gotzsche PC, Vandenbroucke JP, et al. The Strengthening the Reporting of Observational Studies in Epidemiology (STROBE) statement: guidelines for reporting observational studies. Epidemiology. 2007;18:800-4. [18] Beck AT, Ward CH, Mendelson M, Mock J, Erbaugh J. An inventory for measuring depression. Arch Gen Psychiatry. 1961;4:561-71.

[19] Dos Reis FJ, de Barros ESV, de Lucena RN, Mendes Cardoso BA, Nogueira LC. Measuring the Pain Area: An Intra- and Inter-Rater Reliability Study Using Image Analysis Software. Pain Pract. 2016;1:24-30.

[20] Persson AL, Garametsos S, Pedersen J. Computer-aided surface estimation of pain drawings - intra- and inter-rater reliability. J Pain Res. 2011;4:135-41.

[21] Bjorner JB, Thunedborg K, Kristensen TS, Modvig J, Bech P. The Danish SF-36 Health Survey: translation and preliminary validity studies. J Clin Epidemiol. 1998;51:991-9. [22] Bjorner, J. B., M. T. Damsgaard, T. Watt and M. Groenvold (1998). Tests of data quality, scaling assumptions, and reliability of the Danish SF-36. J.Clin.Epidemiol. 51(11): 1001-1011.

[23] Cleland JA, Fritz JM, Childs JD. Psychometric properties of the Fear-Avoidance Beliefs Questionnaire and Tampa Scale of Kinesiophobia in patients with neck pain. Am J Phys Med Rehabil. 2008;87:109-17. 
[24] Jorgensen, M. B., E. Damsgard, A. Holtermann, A. Anke, K. Sogaard and C. Roe (2015). Properties of the Tampa Scale for Kinesiophobia across Workers with Different Pain Experiences and Cultural Backgrounds: A Rasch Analysis. J Appl Meas 16(2): 218-227. [25] Beck AT, Steer RA, Carbin MG. Psychometric properties of the Beck Depression Inventory: Twenty-five years of evaluation. Clin Psychol Rev. 1988;8:77-100. [26] Aalto AM, Elovainio M, Kivimaki M, Uutela A, Pirkola S. The Beck Depression Inventory and General Health Questionnaire as measures of depression in the general population: a validation study using the Composite International Diagnostic Interview as the gold standard. Psychiatry Res. 2012;197:163-71.

[27] McCarthy MJ, Grevitt MP, Silcocks P, Hobbs G. The reliability of the Vernon and Mior neck disability index, and its validity compared with the short form-36 health survey questionnaire. Eur Spine J. 2007;16:2111-7.

[28] Juul, T., K. Sogaard, A. M. Davis and E. M. Roos (2016). Psychometric properties of the Neck OutcOme Score, Neck Disability Index, and Short Form-36 were evaluated in patients with neck pain. J Clin Epidemiol 79: 31-40.

[29] Jull GA, O'Leary SP, Falla DL. Clinical assessment of the deep cervical flexor muscles: the craniocervical flexion test. J Manipulative Physiol Ther. 2008;31:525-33.

[30] Jorgensen R, Ris I, Falla D, Juul-Kristensen B. Reliability, construct and discriminative validity of clinical testing in subjects with and without chronic neck pain. BMC Musculoskelet Disord. 2014;15:408.

[31] Cohen J. Statistical power analysis for the behavioral sciences: Hillsdale, N.J. : L. Erlbaum Associates,; 1988.

[32] Vlaeyen JW, Kole-Snijders AM, Boeren RG, van Eek H. Fear of movement/(re)injury in chronic low back pain and its relation to behavioral performance. Pain. 1995;62:363-72. [33] Vernon H, Mior S. The Neck Disability Index: a study of reliability and validity. J Manipulative Physiol Ther. 1991;14:409-15.

[34] Vernon H, Guerriero R, Kavanaugh S, Soave D, Moreton J. Psychological factors in the use of the neck disability index in chronic whiplash patients. Spine. 2010;35:E16-E21. [35] Carnes D, Ashby D, Underwood M. A systematic review of pain drawing literature: should pain drawings be used for psychologic screening? Clin J Pain. 2006;22:449-57. [36] Bertozzi, L., A. Rosso, A. Romeo, J. H. Villafane, A. A. Guccione, P. Pillastrini and C. Vanti (2015). The accuracy of pain drawing in identifying psychological distress in low back 
pain-systematic review and meta-analysis of diagnostic studies. J Phys Ther Sci 27(10): 3319-3324.

[37] Andersen TE, Karstoft KI, Brink O, Elklit A. Pain-catastrophizing and fear-avoidance beliefs as mediators between post-traumatic stress symptoms and pain following whiplash injury - A prospective cohort study. Eur J Pain. 2016;20:1241-52.

[38] Goldsmith R, Wright C, Bell SF, Rushton A. Cold hyperalgesia as a prognostic factor in whiplash associated disorders: a systematic review. Man Ther. 2012;17:402-10.

[39] Chiu TT, Law EY, Chiu TH. Performance of the craniocervical flexion test in subjects with and without chronic neck pain. J Orthop Sports Phys Ther. 2005;35:567-71.

[40] Shahidi B, Johnson CL, Curran-Everett D, Maluf KS. Reliability and group differences in quantitative cervicothoracic measures among individuals with and without chronic neck pain. BMC Musculoskelet Disord. 2012;13:215.

[41] Bertilson B, Grunnesjo M, Johansson SE, Strender LE. Pain drawing in the assessment of neurogenic pain and dysfunction in the neck/shoulder region: inter-examiner reliability and concordance with clinical examination. Pain Med. 2007;8:134-46.

[42] Cleland JA, Childs JD, Whitman JM. Psychometric properties of the Neck Disability Index and Numeric Pain Rating Scale in patients with mechanical neck pain. Arch Phys Med Rehabil. 2008;89:69-74 


\section{NOTES}

Funding: This study received funding from the Research Fund of the Region of Southern Denmark, the Danish Rheumatism Association, the Research Foundation of the Danish Association of Physiotherapy, Fund for Physiotherapy in Private Practice, and the Danish Society of Polio and Accident Victims (PTU).

Conflicts of interest: The authors declare that they have no competing interests.

Congresses: the study was presented as a poster presentation at the world congress for International Federation of Orthopaedic Manipulative Physical Therapists in 2016 


\section{TITLES OF TABLES}

Table I - Patient characteristics self-reported outcomes and clinical tests

Table II - Correlations between pain extent and self-reported and clinical tests

\section{TITLES OF FIGURES}

Figure 1. - Illustration of the process of digitalising the pain drawing from the paper body chart. A: an original pain drawing, B: Digitalised final pain drawing used to calculate the pain extent. 
Table I Patient characteristics self-reported outcomes and clinical tests

\begin{tabular}{|c|c|c|c|}
\hline & $\begin{array}{l}\text { All patients } \\
(\mathbf{n}=\mathbf{2 0 0})\end{array}$ & $\begin{array}{c}\text { Patients } \\
\text { traumatic onset } \\
(\mathrm{n}=120)\end{array}$ & $\begin{array}{c}\text { Patients non- } \\
\text { traumatic onset } \\
(\mathbf{n}=\mathbf{8 0})\end{array}$ \\
\hline \multicolumn{4}{|c|}{ Patient Reported Outcomes } \\
\hline \multicolumn{4}{|c|}{ mean $(S D)$} \\
\hline SF36-PCS & $35.4(7.6)$ & $35.0(7.1)$ & $36.1(8.2)$ \\
\hline SF36-MCS & $46.4(10.8)$ & $44.7(11.2)$ & $49.0(9.5)$ \\
\hline $\begin{array}{l}\text { TSK } \\
\text { TSJO-NIC }\end{array}$ & $37.8(6.9)$ & $38.5(7.2)$ & $36.8(6.2)$ \\
\hline BDI-II & $13.9(8.7)$ & $15.9(8.8)$ & $10.1(7.8)$ \\
\hline $\begin{array}{l}\text { BDI-11 } \\
\text { NDI }\end{array}$ & $21.3(7.7)$ & $22.8(7.3)$ & $19.0(7.7)$ \\
\hline \multicolumn{4}{|l|}{$\begin{array}{l}\text { Range of Motion degrees } \\
\text { mean (SD) }\end{array}$} \\
\hline Flex & $39.9(15.2)$ & $37.9(15.8)$ & $42.9(13.7)$ \\
\hline Ext & $44.1(19.1)$ & $41.2(20.3)$ & $48.6(16.2)$ \\
\hline Rot L & $58.1(16.3)$ & $56.3(17.6)$ & $60.9(14.0)$ \\
\hline Rot R & $60.1(15.2)$ & $59.1(15.4)$ & $61.8(14.8)$ \\
\hline LF L & $31.4(10.6)$ & $31.1(10.0)$ & $31.7(10.0)$ \\
\hline LF R & $34.1(12.1)$ & $33.6(12.9)$ & $34.8(10.8)$ \\
\hline \multicolumn{4}{|c|}{$\begin{array}{l}\text { Craniocervical Flexion Test } \\
n(\%)\end{array}$} \\
\hline $22 \mathrm{mmHg}$ & $145(72.5)$ & $92(77)$ & $53(66)$ \\
\hline $24 \mathrm{mmHg}$ & $36(18.0)$ & $23(19)$ & $13(16)$ \\
\hline $26-30 \mathrm{mmHg}$ & $19(9.5)$ & $5(4)$ & $14(18)$ \\
\hline \multicolumn{4}{|l|}{ Cervical Extension Test } \\
\hline \multicolumn{4}{|l|}{$n(\%)$} \\
\hline $0-10 \mathrm{sec}$ & $32(16.0)$ & $22(18)$ & $10(12)$ \\
\hline $11-28 \mathrm{sec}$. & $55(27.5)$ & $40(33)$ & $15(19)$ \\
\hline $39-119$ sec. & $28(14.0)$ & $16(13)$ & $12(15)$ \\
\hline $120 \mathrm{sec}$. & $85(42.5)$ & $42(35)$ & $43(53)$ \\
\hline \multicolumn{4}{|l|}{$\begin{array}{l}\text { Pain extent median } \\
\text { mean }(S D)\end{array}$} \\
\hline $\begin{array}{l}\text { percentage of total body } \\
\text { chart }\end{array}$ & $7.5(6.7)$ & $7.6(6.7)$ & $7.4(6.8)$ \\
\hline \multicolumn{4}{|c|}{$\begin{array}{l}\text { SF36-PCS = Short Form 36, Standardised Physical Component Summary Score; SF36- } \\
\text { MCS = Short Form 36, Standardised Mental Component Summary Score; TSK = Tampa } \\
\text { Scale of Kinesiophobia; BDI-II = Beck Depression Inventory-II; NDI = Neck Disability } \\
\text { Index; Flex = Cervical Flexion; Ext = Cervical Extension; Rot L = Cervical Rotation Left; } \\
\text { Rot R = Cervical Rotation Right; LF L = Cervical Lateral Flexion Left; LF R = Cervical } \\
\text { Lateral Flexion Right; } n=\text { number, SD = Standard Deviation }\end{array}$} \\
\hline
\end{tabular}


Table II Correlation pain extent and self-reported outcomes and clinical tests

\begin{tabular}{llll}
\hline Variable & $\begin{array}{l}\text { All patients } \\
\boldsymbol{r}(\mathbf{p}-\mathbf{v a l u e})\end{array}$ & $\begin{array}{l}\text { Patients traumatic } \\
\text { onset } \\
\boldsymbol{r}(\mathbf{p} \text {-value) }\end{array}$ & $\begin{array}{l}\text { Patients non-traumatic } \\
\text { onset } \\
\boldsymbol{r} \text { (p-value) }\end{array}$ \\
\hline $\begin{array}{l}\text { Patient reported } \\
\text { outcomes }\end{array}$ & & \\
SF36-PCS & $-0.03(0.72)^{*}$ & $-0.04(0.69)$ & $-0.01(0.96)$ \\
SF36-MCS & $-0.15(0.83)^{*}$ & $-0.15(0.12)$ & $-0.16(0.15)$ \\
TSK & $0.21(0.01)^{*}$ & $0.12(0.21)$ & $0.33(0.01)^{*}$ \\
BDI-II & $0.29(<0.01)^{*}$ & $0.21(0.02)^{*}$ & $0.40(<0.01)^{*}$ \\
NDI & $0.33(<0.01)^{*}$ & $0.22(0.02)^{*}$ & $0.45(<0.01)^{*}$ \\
\hline Range of & & & \\
Motion & & & $-0.04(0.75)$ \\
Fl & $-0.05(0.50)$ & $-0.05(0.63)$ & $-0.12(0.30)$ \\
Ext & $-0.05(0.45)$ & $-0.01(0.91)$ & $-0.11(0.34)$ \\
Rot L & $-0.10(0.15)$ & $-0.08(0.37)$ & $-0.06(0.62)$ \\
Rot R & $-0.11(0.15)$ & $-0.14(0.15)$ & $-0.02(0.87)$ \\
LF L & $0.01(0.94)$ & $-0.01(0.98)$ & $0.09(0.45)$ \\
LF R & $0.04(0.59)$ & $-0.01(0.99)$ & $-0.31(0.01)^{*}$ \\
\hline Muscle function & & & $-0.29(0.01)^{*}$ \\
CCFT & $-0.24(<0.01)^{*}$ & $-0.18(0.06)$ & \\
CE & $-0.19(0.01)^{*}$ & $-0.12(0.21)$ & \\
\hline
\end{tabular}

$*=$ significant correlations

SF36-PCS = Short Form 36, Standardised Physical Component Summary Score; SF36MCS = Short Form 36, Standardised Mental Component Summary Score; TSK = Tampa Scale of Kinesiophobia; BDI-II = Beck Depression Inventory-II; NDI = Neck Disability Index; Flex = Cervical Flexion; Ext $=$ Cervical Extension; Rot $L=$ Cervical Rotation Left; Rot $\mathrm{R}=$ Cervical Rotation Right; LF L $=$ Cervical Lateral Flexion Left; LF R = Cervical Lateral Flexion Right; CCFT $=$ Craniocervical Flexion Test; $\mathrm{CE}=$ Cervical Extension; $\mathrm{n}=$ number. 

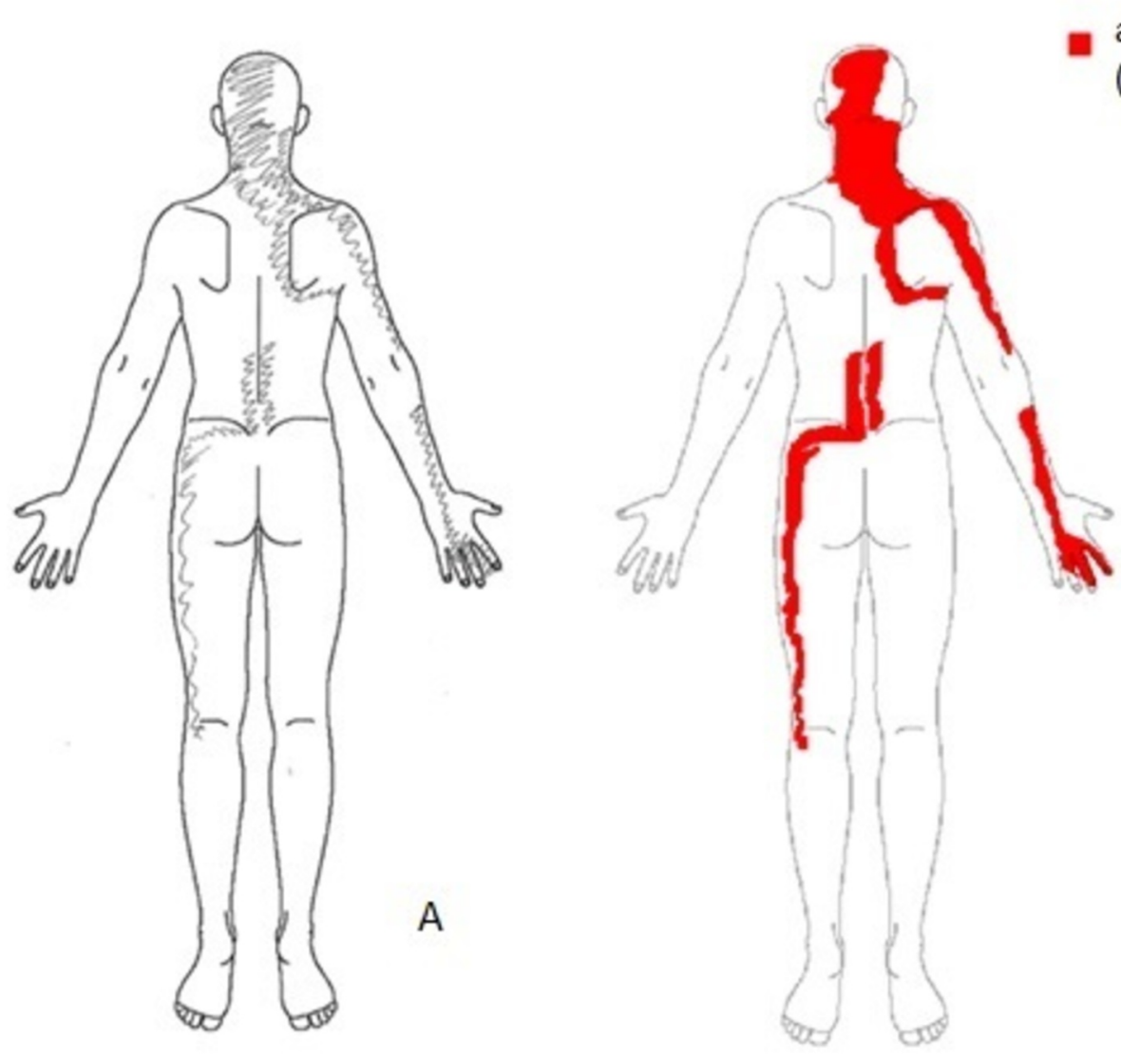

area 21459 pixels

( $15 \%$ bodychart )

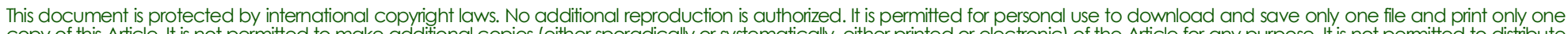

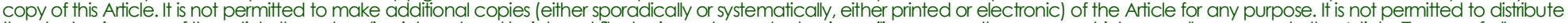

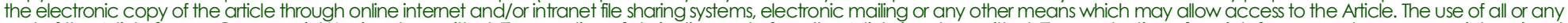

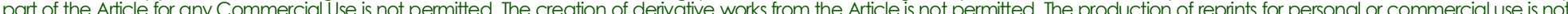

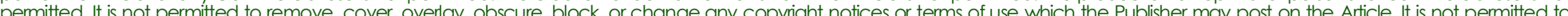
frame 